\title{
Water Clear Parathyroid Adenoma: A Report of 2 Cases
}

\author{
Subhash C Yadav*, Kritika Singh and Pragati Sathe \\ Department of Pathology, Seth G. S. Medical College, Parel, Mumbai, India
}

\begin{abstract}
Hyperparathyroidism occurs mainly due to parathyroid hyperplasia, adenoma and rarely carcinoma. Most of the adenomas are composed of chief cells. Water clear cell adenoma is a rare phenomenon. We are sharing two cases of parathyroid adenomas composed entirely of water clear cells and require high degree to suspicion to identify them as they have low endocrinological activity.
\end{abstract}

Keywords: Water Clear Cell, Parathyroid Adenoma, Rare, Low Endocrinologic Activity

\section{Introduction}

Primary hyperparathyroidism, a parathyroid abnormality can be divided into three histological types: adenoma, hyperplasia and carcinoma with relative frequencies as $77.9 \%, 14.6 \%$ and $4.8 \%$ respectively. Solitary adenoma is the most common cause of primary hyperparathyroidism. Multiple adenomas can occur, but are extremely rare. Most of these adenomas are composed of chief cells or mixed cells. Oxyphil adenomas are rarer than chief cell adenomas. Water clear cell adenomas are even rarer causes of parathyroid adenoma with approximately 10 cases reported in the literature till now. We report two cases of primary hyperparathyroidism due to water clear cell adenomas which one should be aware of. ${ }^{[1-3]}$

\section{Case Report}

CASE 1: A 65- year- old diabetic female, presented with generalised bodyache and inability to stand from sitting position since 3 months. She underwent modified radical mastectomy followed by chemotherapy for right breast carcinoma a year back. Patient was evaluated and found to have hypercalcemia $(11.9 \mathrm{mg} / \mathrm{dl})$ with low serum phosphorus levels $(2.1 \mathrm{mg} / \mathrm{dl})$ and high serum parathyroid hormone $(\mathrm{PTH})$ levels $(254 \mathrm{pg} / \mathrm{ml})$. Bone scan did not suggest metastasis. Contrast enhanced computed tomography of neck showed $13 \times 10 \mathrm{~mm}$ left inferior parathyroid adenoma with scintigraphic evidence of methoxyisobutylisonitrile (MIBI) avid lesion in the corresponding area. Subsequently, left inferior parathyroidectomy was done. Grossly, the received specimen measured $2 \times 1.5 \times 0.8 \mathrm{~cm}$ and weighed $1.81 \mathrm{gms}$.

CASE 2: A 28- year-old female, presented with five month history of left hip pain. There was no history of renal calculi, fracture, irregular menses or a significant family history. Magnetic resonance imaging showed a $6 \times 2.5 \times 1.8 \mathrm{~cm}$ well defined, lytic lesion involving left proximal femoral metadiaphysis suggestive of fibrous dysplasia. Laboratory tests revealed elevated serum calcium levels $(11.9 \mathrm{mg} / \mathrm{dl})$, low serum phosphorus levels $(2.4 \mathrm{mg} / \mathrm{dl})$ and markedly increased serum PTH level of $483 \mathrm{pg} / \mathrm{ml}$. Triple phase venous computed tomography scan showed a right inferior parathyroid adenoma and MIBI confirmed uptake in the same region. The right inferior parathyroid gland was excised. Grossly, the gland measured $3 \mathrm{~cm} \times 1 \mathrm{~cm} \times 0.5 \mathrm{~cm}$ weighing 2.47 grams.

Microscopic examination in both cases revealed encapsulated parathyroid neoplasms composed of tumour cells arranged in acinar pattern with few nests and sheets. (Fig 1a,1b) Monomorphic cells had basally located nuclei and abundant supranuclear clear cytoplasm. Focal anisonucleosis noted. (Fig 2a,2b,2c) Lesion was devoid of mature adipose tissue and a rim of compressed normal parathyroid gland tissue was seen at the periphery. The cytoplasm of these cells were positive for periodic acid Schiff (PAS) stain. (Fig 2d) There was no evidence of capsular or vascular invasion. Based on these histological findings, diagnosis of water-clear adenoma of parathyroid gland was given. Post operatively, calcium levels of both patients dropped to normal. Presently, they are on oral calcium supplementation and have been advised regular follow up.

\section{Discussion}

Primary hyperparathyroidism is a common endocrine disorder with an incidence of 21.6 per 1,00,000 person years. Elevated serum calcium levels without associated symptoms are seen in approximately $80 \%$ of newly diagnosed cases of primary hyperparathyroidism. ${ }^{[2]}$ Parathyroid adenomas, usually single however multiple adenomas, either unilateral or bilateral have been described and sometimes it is difficult to distinguish multiple adenomas from hyperplasia. Patients with multiple adenomas have relatively higher PTH levels ${ }^{[3]}$ Histologically, parathyroid 


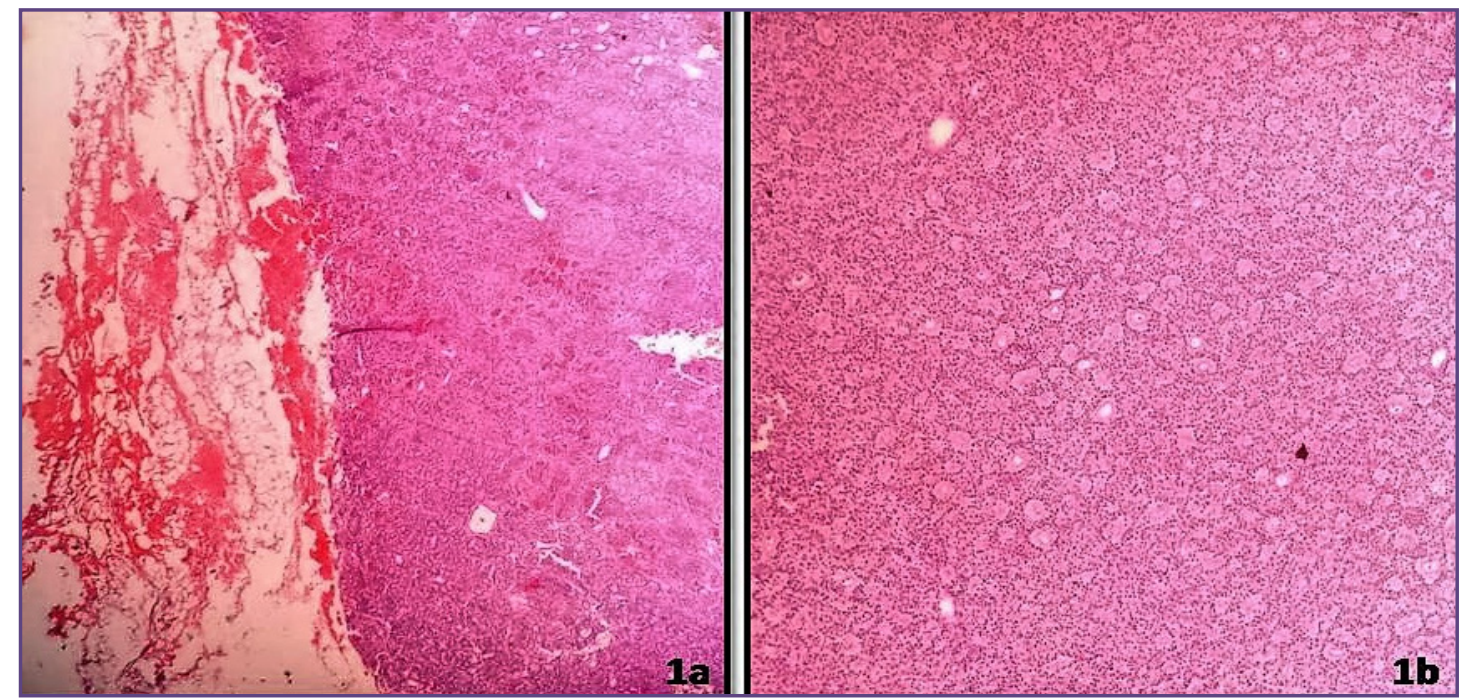

Fig. 1a: Low power view showing an encapsulated parathyroid neoplasm (HE 100X). Fig. 1b: The tumour cells are predominantly arranged in acinar pattern with few nests and sheets (HE 100X).

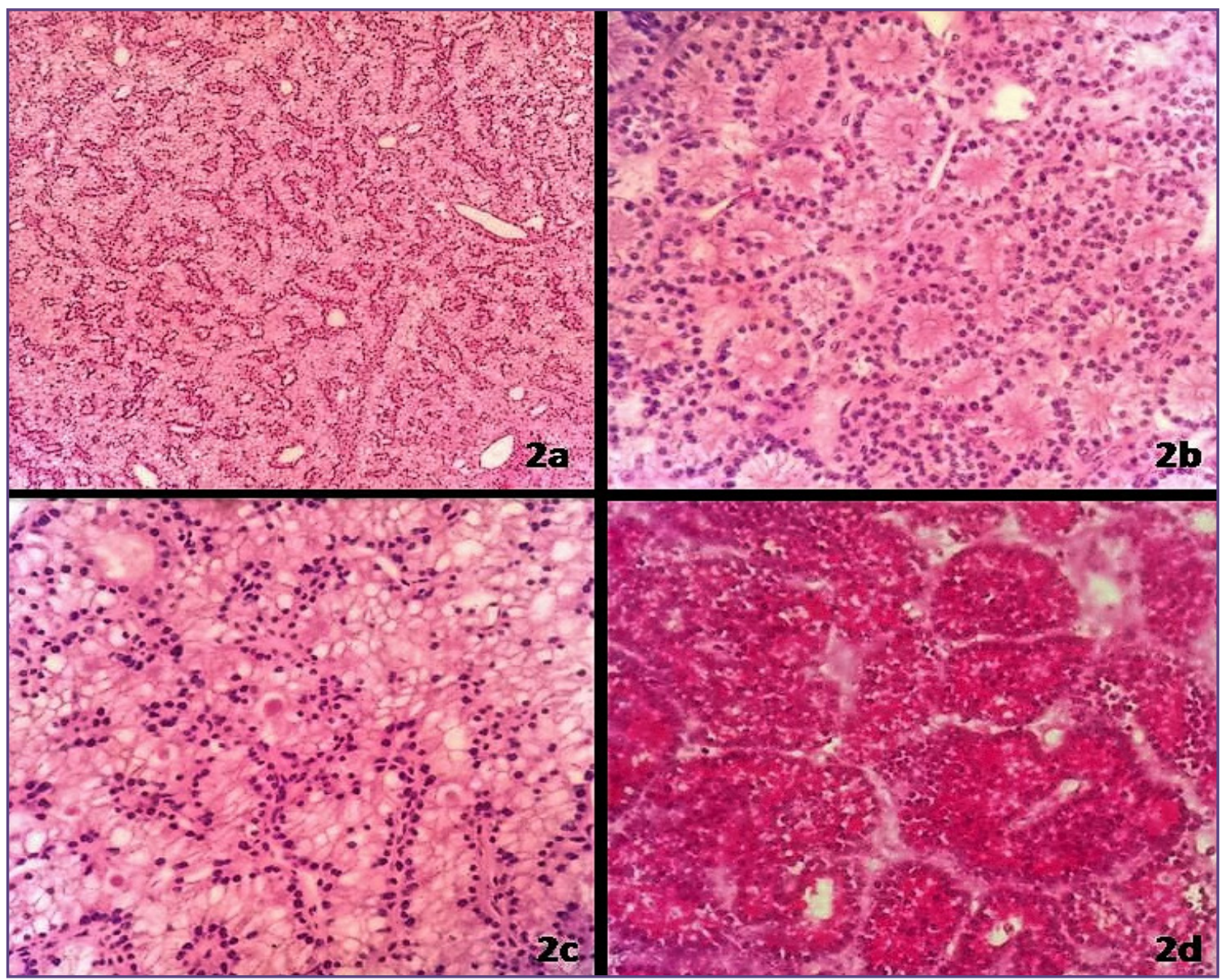

Fig. 2a, 2b \& 2c: High power view showing benign parathyroid neoplasms with predominant acinar pattern composed of monomorphic cells with basally located nuclei and abundant supranuclear watery clear cytoplasm (HE 400x) Fig. 2d: The cytoplasm of these cells were PAS positive indicating presence of glycogen (PAS 400X). 
adenomas are composed of functioning parathyroid tissue containing single population of cells, consisting primarily of chief cells but can be sometimes mixed. ${ }^{[2]}$

Described by Kovack's, water clear cell parathyroid adenoma are very rare neoplasm with vacuolated to optically clear cytoplasm due to vesicles containing glycogen. It is not difficult to differentiate water clear cell adenoma (WCCA) from water clear cell hyperplasia $(\mathrm{WCCH})$ as $\mathrm{WCCH}$ involves all the glands and WCCA is usually solitary. However, due to unequivocal distribution, sometimes it may be difficult to differentiate. ${ }^{[1,2]} \mathrm{WCCH}$ is also extremely rare however, unlike chief cell hyperplasia, it is not associated with any endocrine syndromes nor does it have a malignant potential connotation. ${ }^{[4]} \mathrm{WCCH}$ with primary hyperparathyroidism was first described in 1934 by Albright et al. For reasons unknown, there has been a steady decline in the incidences of WCCH \& WCCA from $6.8 \%$ to $4.9 \%$, and finally to less than $1 \%{ }^{[5-6]}$

Water clear cells are not seen in normal parathyroid gland and its presence is usually associated with hyperfunctioning of gland. The proportion of these clear cells increases with advancing age and they probably represent transformed chief cells. Classically, WCCH starts in the superior parathyroid gland first and then involves the inferior parathyroid gland. ${ }^{[4]}$

Electron microscopy done by Kovac, showed prominent glycogen deposits in the cytoplasm and cellular structures called annulate lamellae with rail like configuration. Holzman \& Lange described numerous membrane limited vacuoles $1-5 \mu$ in diameter with occasional dense body, containing a finely particulate thread-like material. None of the authors demonstrated these findings in the normal parathyroid cells. The five theoretical possibilities for the origin of these vacuoles are dilated golgi bodies, dilated sacs of endoplasmic reticulum, swollen mitochondria, de novo produced by the cell or pinocytic or lysosomal vesicles. $^{[3,5]}$

Water clear cell type has most histologic features similar to a regular adenoma i.e. circumpscription, presence of a thin fibrous capsule and presence of a rim of relatively normal extra-capsular parathyroid tissue. Unlike its name, the WCCs are seldom entirely "clear" and are often variably vacuolated, foamy, granular and clear. ${ }^{[1,6]}$ The differential diagnosis considered are chief cell adenoma with extensive clear cell change. However, the entire tumor should not be replaced by clear cells and the clear cells of chief cell adenoma contains glycogen, which is PAS diastase sensitive. According to one report by Grenko et al. the water clear cell adenoma is negative for glycogen. Other differential diagnoses that can be considered are metastatic renal cell carcinoma, paraganglioma and clear cell change in salivary gland tumor like acinar cell carcinoma and mucoepidermoid carcinoma. Immunohistochemistry should be therefore done in suspected cases. ${ }^{[1]}$ Despite high levels of parathyroid hormones, serum calcium levels are not markedly increased in cases of WCCA until they reach a large size indicating that these adenomas have low endocrinological activity as suggested by Kanda et al. ${ }^{[2]}$

\section{Conclusion}

The aim of this report is to draw attention to this uncommon variant of parathyroid adenoma seen in two cases composed entirely of water clear cells that has low endocrinologic potential and hence needs high level of suspicion.

\section{Reference}

1. Liang Y. Mojica W. Chen F Water-Clear Cell Adenoma of Parathyroid Gland: A Case Report and Literature Review: N A J Med Sci. 2010;3(4):194-198

2. Piggott R. Water P. Ashraf J. Colesky F. Kerin M.J. Waterclear cell adenoma: A rare form of hyperparathyroidism Int J Surg Case Rep. 2013; 4(10): 911-913

3. Kazuko K. Yosuke O. Takahisa T, et. Al. A rare case of primary hyperparathyroidism with clear cell adenoma: Endocrine journal 2004;51: 207-212,

4. Ezzat T, Maclean G, Parameswaran R, et al. Primary hyperparathyroidism with water clear cell content: the impact of histological diagnosis on clinical management and outcome. Annals of The Royal College of Surgeons of England. 2013;95(3):e60-e62.

5. Roth SI. The ultrastructure of primary water-clear cell hyperplasia of the parathyroid glands. Am J Pathol. 1970;61(2):233-48

6. Kuhel WI, Gonzales D, Hoda SA, Pan L, Chiu A, Giri D, DeLellis RA. Synchronous water-clear cell double parathyroid adenomas a hitherto uncharacterized entity? Arch Pathol Lab Med. 2001;125(2):256-9

*Corresponding author:

Dr. Yadav Subhash C., Department of Pathology, Seth G.S.Medical College, Parel, Mumbai-400012. India.

Phone: +91 9833844678

Email: drsubhashyadav23@gmail.com

Financial or other Competing Interests: None.

Date of Submission : 01.10.2016

Date of Acceptance : 15.03.2017

Date of Publication : 29.05.2017 